\title{
openheart Acarbose, lente carbohydrate, and prebiotics promote metabolic health and longevity by stimulating intestinal production of GLP-1
}

\author{
Mark F McCarty, ${ }^{1}$ James J DiNicolantonio ${ }^{2,3}$
}

To cite: McCarty MF, DiNicolantonio JJ. Acarbose, lente carbohydrate, and prebiotics promote metabolic health and longevity by stimulating intestinal production of GLP-1. Open Heart 2015;2:e000205. doi:10.1136/openhrt-2014000205

Received 2 October 2014 Revised 1 December 2014 Accepted 12 January 2015

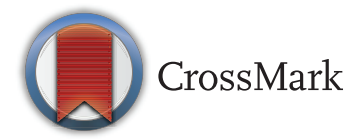

${ }^{1}$ Catalytic Longevity, Encinitas, California, USA ${ }^{2}$ Mid America Heart Institute, St. Luke's Hospital, Kansas City, Missouri, USA

${ }^{3}$ Wegmans Pharmacy, Ithaca, New York, USA

Correspondence to Dr Mark F McCarty; markfmccarty@gmail.com

\section{ABSTRACT}

The $\alpha$-glucosidase inhibitor acarbose, which slows carbohydrate digestion and blunts postprandial rises in plasma glucose, has long been used to treat patients with type 2 diabetes or glucose intolerance. Like metformin, acarbose tends to aid weight control, postpone onset of diabetes and decrease risk for cardiovascular events. Acarbose treatment can favourably affect blood pressure, serum lipids, platelet aggregation, progression of carotid intima-media thickness and postprandial endothelial dysfunction. In mice, lifetime acarbose feeding can increase median and maximal lifespan - an effect associated with increased plasma levels of fibroblast growth factor 21 (FGF21) and decreased levels of insulin-like growth factor-I (IGF-I). There is growing reason to suspect that an upregulation of fasting and postprandial production of glucagon-like peptide-1 (GLP-1)—stemming from increased delivery of carbohydrate to $L$ cells in the distal intestinal tract-is largely responsible for the versatile health protection conferred by acarbose. Indeed, GLP-1 exerts protective effects on vascular endothelium, the liver, the heart, pancreatic $\beta$ cells, and the brain which can rationalise many of the benefits reported with acarbose. And GLP-1 may act on the liver to modulate its production of FGF21 and IGF-I, thereby promoting longevity. The benefits of acarbose are likely mimicked by diets featuring slowly-digested 'Iente' carbohydrate, and by certain nutraceuticals which can slow carbohydrate absorption. Prebiotics that promote colonic generation of short-chain fatty acids represent an alternative strategy for boosting intestinal GLP-1 production. The health benefits of all these measures presumably would be potentiated by concurrent use of dipeptidyl peptidase 4 inhibitors, which slow the proteolysis of GLP-1 in the blood.

\section{ACARBOSE THERAPY PROMOTES VASCULAR HEALTH}

Acarbose is an $\alpha$-glucosidase inhibitor prescribed for prevention and treatment of diabetes; it and metformin are the most commonly used diabetes drugs worldwide. Less than $2 \%$ of acarbose is absorbed after administration, rationalising its non-toxicity; its clinical utility evidently reflects its ability to slow absorption of dietary carbohydrate by acting within the intestinal tract to inhibit brush-border $\alpha$-glucosidase, which plays a key role in the digestion of starch and sugars. ${ }^{12}$ Inhibition of $\alpha$-glucosidase in saliva, and non-competitive inhibition of pancreatic $\alpha$-amylase, also contribute to it slowing of carbohydrate absorption. ${ }^{3}$ Clinical doses of acarbose ingested with meals notably blunt the postprandial increase in serum glucose, a well-documented predictor of macrovascular and microvascular complications in diabetics, and of macrovascular risk in non-diabetics. ${ }^{45}$ A Cochrane meta-analysis found that, on average, acarbose therapy lowers glycated haemoglobin (HbA1c) levels by $0.8 \%$, and reduces the postprandial increase in plasma glucose by $2.3 \mathrm{mM}^{6}{ }^{6}$ Glycaemic control benefits of acarbose therapy tend to be greater in Asian clinical trials than in Western ones, likely because Asians tend to consume diets higher in carbohydrates. ${ }^{7}$ Gastrointestinal side effects of acarbose-reflecting carbohydrate malabsorption-are fairly common when initiating therapy, but tend to lessen over time as the distal intestine upregulates its capacity to absorb glucose. These side effects can be minimised by starting with a low dose-25 or $50 \mathrm{mg}$ with two or three meals daily-and gradually raising it; in other words, 'start low, go slow'. 8 The maximal dose of acarbose is $100 \mathrm{mg}$ three time a day-higher doses do not achieve a greater impact on carbohydrate digestion.

Like metformin, but unlike many other diabetes drugs, acarbose tends to promote weight loss, and cannot trigger hypoglycaemic episodes. ${ }^{9-11}$ Acarbose also resembles metformin in that there is reasonably compelling evidence that acarbose therapy in patients with diabetes or glucose intolerance has a 
favourable impact on cardiovascular health outcomes, and can slow the onset of diabetes in glucose-intolerant participants. ${ }^{2} 1213$ Analyses of long-term outcomes in the Stop Non-insulin-dependent Diabetes Mellitus (STOP-NIDDM) trial, as well as a meta-analysis of longer-term controlled trials of acarbose in type 2 diabetics, conclude that risk for cardiovascular events, most notably myocardial infarction, is lower in acarbose-treated patients $(\mathrm{HR}=0.51 ; 95 \% \mathrm{CI}$ 0.28 to 0.95 in STOP-NIDDM and HR=0.66; CI 0.48 to 0.88 in the diabetes treatment meta-analysis). ${ }^{14}{ }^{15} \mathrm{~A}$ large multicenter controlled trial in China ongoing since 2009, the Acarbose Cardiovascular Evaluation study, should provide a more definitive determination of acarbose's capacity to promote vascular health. ${ }^{16}$

Acarbose therapy can favourably influence cardiovascular risk factors. In diabetics, acarbose therapy tends to lower mean blood pressure; in the STOP-NIDDM trial, incidence of newly diagnosed hypertension was $34 \%$ lower in the acarbose-treated group. ${ }^{14}{ }^{17}$ Yet acarbose therapy also helps to prevent postprandial hypotension in elderly participants prone to this disorder. ${ }^{18} 19$ Serum triglyceride levels tend to drop, and high-density lipoprotein cholesterol to rise, during acarbose therapy. ${ }^{13}{ }^{14}$ In early type 2 diabetes, acarbose therapy decreases urinary markers of platelet aggregation. ${ }^{20}$ Slowed progression of carotid intima-media thickness has also been reported in acarbosetreated patients, and acarbose therapy improves postprandial endothelium-dependent vasodilation. ${ }^{21-24}$ In rabbits subjected to $30 \mathrm{~min}$ of coronary occlusion followed by reperfusion, feeding acarbose for a week prior to the procedure was associated with a greater than $50 \%$ reduction in infarct size; this benefit was wholly abolished if an inhibitor of ATP-sensitive K channels (5-hydroxydecanoate) was administered slightly before onset of ischaemia. ${ }^{25}$

\section{ACARBOSE EXTENDS LONGEVITY AND MODULATES FGF21 AND INSULIN-LIKE GROWTH FACTOR-I (IGF-I) IN MICE}

There is now reason to suspect that, beyond its clear utility in those who are glucose intolerant, acarbose may have broader potential for health promotion. In a lifetime feeding study in mice, addition of $0.1 \%$ acarbose to a standard diet $(65 \%$ of calories from grain carbohydrates, $22 \%$ protein), beginning at 4 months of age, was associated with significant increases in the median and maximal lifespan, in males and females. ${ }^{26}$ The increase in median lifespan was greater in males than females$22 \%$ vs 5\%; maximal lifespan increased $11 \%$ and $9 \%$ in males and females, respectively. Curiously, acarbose feeding did not influence the HbAlc level in these mice, likely because their fasting glucoses were slightly higher, balancing out the likely impact of acarbose on postprandial glucose. Since these mice were not diabetic or diabetes prone, it is not immediately apparent why slowing dietary glucose absorption would have such a notable impact on longevity in mice.

However, the researchers uncovered two key cluesserum FGF21 was significantly higher, and serum insulin- like growth factor-I (IGF-I) significantly lower in the acarbose-treated mice. ${ }^{26}$ Systemic IGF-I activity is a clear driver of the aging process and determinant of longevity in mice $;^{27}$ moreover, FGF21 acts on the liver to blunt hepatic sensitivity to growth hormone, thereby decreasing the liver's production of IGF-I. ${ }^{28-30}$ Transgenic mice with a constitutive increase in FGF21 production enjoy a substantial increase in mean and maximal lifespan, an effect likely mediated in part by downregulation of IGF-I activity. $^{31} 32$

An effect of acarbose on hepatic FGF21 production has not previously been reported. However, by diverting additional glucose to the distal intestine, chronic therapy with acarbose or other $\alpha$-glucosidase inhibitors boosts the production of glucagon-like peptide-1 (GLP-1) by intestinal L cells. ${ }^{33-38}$ There are several reports that long-acting agonists for the GLP-1 receptor increase hepatic FGF21 production. ${ }^{39} 40$ PPAR $\alpha$, after deacetylation by Sirt1, interacts with the FGF21 promoter to stimulate transcription of this hormone. ${ }^{1-45}$ Notably, GLP-1 agonist drugs are reported to increase expression of PPAR $\alpha$ and Sirt1 in hepatocytes. ${ }^{46-48}$ Hence, these findings suggest that the upregulation of GLP-1 consequent to chronic acarbose treatment may act on the liver to promote transcriptional activation of FGF21, which in turn suppresses IGF-I production.

\section{ACARBOSE BENEFITS REFLECT SUPPRESSION OF POSTPRANDIAL GLYCAEMIA AND UPREGULATION OF GLP-1}

In light of current evidence, two phenomena appear to interact in mediating acarbose's favourable health impacts-a suppression of postprandial surges in plasma glucose, and an increased production of GLP-1. A rapid elevation of plasma glucose levels imposes an oxidative stress on vascular endothelium that compromises the protective function of endothelial nitric oxide synthase (eNOS) and promotes inflammation; this effect is associated with an acute reduction in endotheliumdependent vasodilation. ${ }^{49}$ This oxidative stress can originate from $\mathrm{NADPH}$ oxidase, uncoupled eNOS, and mitochondria. ${ }^{50-52}$ Curiously, episodic large rises in glucose appear to have a more notable impact in this regard than sustained elevations of glucose; hence, blunting the postprandial glucose rise may be particularly worthwhile as a strategy for protecting the vasculature from oxidative stress. ${ }^{49} \quad 53 \quad 54$ Moreover, since acarbose therapy does not risk provoking hypoglycaemic reactions, it might be viewed as a strategy for stabilising glucose levels in diabetics, avoiding the wild swings in glycaemia that may be particularly noxious for vascular health. As noted, postprandial glucose predicts risk for microvascular and macrovascular complications in type 2 diabetics more effectively than fasting glucose; it also predicts vascular risk in glucose-intolerant nondiabetics. ${ }^{45}$ While some of this risk likely is attributable to metabolic factors that induce this glucose intolerance, 
there is also good reason to suspect that the pro-oxidative impact of postprandial hyperglycaemia per se is a key mediator of this risk. Moreover, episodic hyperglycaemia, in conjunction with elevated free fatty acids, also exerts an oxidant effect on pancreatic $\beta$ cells; in pre-diabetics, this 'glucolipotoxicity' can lead to the failure of glucose-stimulated insulin secretion and $\beta$-cell apoptosis that ushers in clinical diabetes. ${ }^{55}$ Hence, moderation of postprandial hyperglycaemia may be largely responsible for acarbose's ability to slow diabetes onset.

However, the ability of acarbose treatment to up-regulate GLP-1 production may also be a key mediator of its health benefits. A recent 24-week study in type 2 diabetics found that fasting and postprandial plasma concentrations of GLP-1 were about $10 \%$ and 20\% higher, respectively, during acarbose therapy. ${ }^{38}$ GLP-1 acts directly on vascular endothelium to boost eNOS activity, ${ }^{56-58}$ in the 24-week study, changes in GLP-1 levels correlated directly with increases in serum nitric oxide. ${ }^{38}$ Activation of AMPK also contributes to GLP-1's favourable influence on endothelial function. ${ }^{59}$ GLP-1 acts directly on the liver to promote fatty acid oxidation and inhibit fatty acid synthesis; ${ }^{47} 60$ GLP-1 receptor agonists have a favourable impact on models of nonalcoholic fatty liver disease in rodents, and also have a favourable effect on this syndrome in humans. ${ }^{46} 61-64$ The clinical impact of acarbose on non-alcoholic fatty liver disease still requires evaluation. ${ }^{65}$ As we have seen, the effects of acarbose treatment on hepatic production of FGF21 and IGF-I in healthy mice might well be attributable to increased GLP-1 production.

The tendency of acarbose to promote weight loss is shared by long-lasting GLP-1 receptor mimics currently used in diabetes therapy; indeed, these agents can aid weight loss in non-diabetics as well. ${ }^{66}{ }^{67}$ Hence, it is reasonable to suspect that GLP-1 is a mediator of the favourable impact of acarbose therapy on weight control.

Studies with long-lived GLP-1 agonists in rodents demonstrate that pretreatment with these agents ameliorate the impact of ischaemia reperfusion on the heart. ${ }^{68-72}$ This protective effect is blocked by concurrent administration of inhibitors of mitochondrial ATP-sensitive $\mathrm{K}$ channels $\left(\mathrm{mK}_{\mathrm{ATP}}\right){ }^{72}$ Ischaemic preconditioning likewise protects the heart from ischaemia-reperfusion by up-regulating activity of $\mathrm{mK}_{\mathrm{ATP}}$ channels. ${ }^{73}$ The opening of these channels during ischaemia lessens the potential gradient driving calcium influx into mitochondria, preventing an excessive rise in intramitochondrial calcium that severely compromises mitochondrial function. ${ }^{39} 47$ The fact that acarbose pretreatment of normal healthy rabbits markedly decreases infarct size following myocardial ischaemia reperfusion-a benefit blocked by acute administration of an $\mathrm{mK}_{\mathrm{ATP}}$ inhibitor-suggests that, by raising GLP-1 production, acarbose exerts a protective effect on the heart mechanistically analogous to ischaemic preconditioning. ${ }^{25}$

In addition to acting directly on pancreatic $\beta$ cells to potentiate glucose-stimulated insulin release, GLP-1 also acts on these cells in various ways to counteract glucolipotoxicity. ${ }^{74-78}$ Hence, increased GLP-1 production may collaborate with a decrease in postprandial glucose to mediate acarbose's diabetes preventive action.

Brain neurons express GLP-1 receptors, and rodent studies with long-lived GLP-1 receptor agonists indicated that these agents can protect neurons from ischaemic damage, support effective learning, and diminish memory impairment in mouse models of Alzheimer's disease. ${ }^{79-86}$ Since these agents are effective in these regards when administered intraperitoneally, it is conceivable that chronic upregulation of intestinal GLP-1 production could modestly benefit brain health.

In summary, GLP-1 acts directly on the vasculature, liver, myocardium, $\beta$ cells, and brain to safeguard the structural and functional integrity of these organswhile aiding weight control and modulating FGF21 and IGF-I in a way likely to slow aging and promote longevity; these interactions are summarised in figure 1. Acarbose therapy, or other measures which safely up-regulate intestinal GLP-1 production, may provide protection in these respects. And there is no reason to believe that such benefits will only be achievable in the context of glucose intolerance; upregulation of GLP-1 production might be viewed as an 'anti-aging' strategy of benefit to the general population. Of course, acarbose is likely to provide greater net protection in glucose-intolerant participants, owing to its favourable influence on their excessive postprandial glucose excursions.

\section{ALTERNATIVE OR COMPLEMENTARY STRATEGIES FOR ACHIEVING ANALOGOUS HEALTH BENEFITS}

Since acarbose, for practical purposes, is not absorbed, and its physiological effects hence reflect a slowing of dietary carbohydrate digestion, it is reasonable to suspect that choosing a diet in which slow-digesting 'lente' carbohydrate predominates should achieve
Figure 1 Potential health benefits of lente carbohydrate/ acarbose. GLP, glucagon-like peptide-1; FGF21, fibroblast growth factor 21; IGF-I, insulin-like growth factor-I; eNOS, endothelial nitric oxide synthase; FFA, free fatty acids; SCFA, short-chain fatty acids.

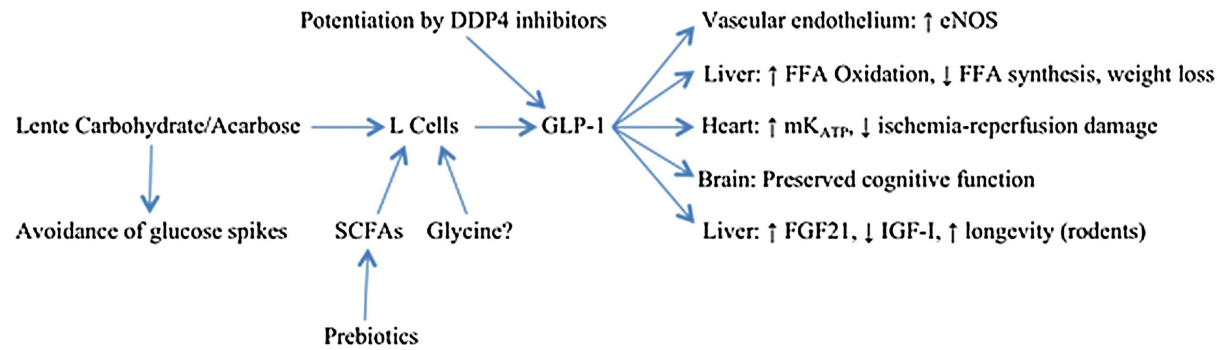


benefits comparable to those of acarbose therapy. ${ }^{87} 88$ Pasta, boiled beans, structurally intact grain kernels and sprouted grains-as contrasted to most flour or sugar products-are more difficult to digest and have a notably lower glycaemic index. ${ }^{89}$ Arguably, complementing such dietary choices with a low dose of acarbose (perhaps $25 \mathrm{mg}$ per meal?) would be an appropriate strategy for minimising postprandial glycaemic excursion while boosting GLP-1 production.

Nutraceutical measures for delaying digestion of dietary carbohydrate, including administration of adequate doses of the highly viscous soluble fibre glucomannan, or of amylase-inhibitory phytochemicals extracted from beans, might be expected to mimic the health benefits achievable by acarbose or other pharmaceutical $\alpha$-glucosidase inhibitors (eg, miglitol, voglibose). ${ }^{90-98}$ Glucomannan has the potential drawback of impeding the absorption of certain coadministered drugs or fat-soluble vitamins; hence, its use may be incompatible with some drugs that must be administered with meals. ${ }^{99} 100$ Prebiotics can promote colonic production of GLP-1, as the short-chain fatty acids produced by properly nourished gut bacteria act on L cells to stimulate release of GLP-1. ${ }^{101-106}$ Hence, prebiotics such as inulin or resistant starch may mimic the GLP-1-mediated benefits of acarbose, though they could not be expected to notably influence postprandial glucose levels. Consideration should also be given to the possibility that dietary glycine might act on L cells to stimulate GLP-1 release; high physiological concentrations of glycine, via activation of glycine-gated chloride channels, have this effect on an L-cell-derived cell line. ${ }^{107}$ Such an effect might explain the ability of glycine supplementation to prevent metabolic syndrome and fatty liver in sucrose-fed rats. ${ }^{108-110}$

The up-regulatory impact of any of these measures on GLP-1 levels should be considerably potentiated by concurrent administration of dipeptidyl peptidase 4 (DPP4) inhibitors-for example, sitagliptin, vildagliptin-which slow the proteolytic degradation of GLP-1 in plasma. ${ }^{111}$

In overview, it appears that achieving slow digestion of dietary carbohydrate-either by choosing 'lente' carbohydrate foods, or by pharmacological inhibition of carbohydrate digestion, as with acarbose-can exert a range of favourable effects on health and longevity by up-regulating GLP-1 production and concurrently blunting the pro-oxidative effect of postprandial glucose elevations. Prebiotics can also be employed to boost GLP-1 production, and concurrent treatment with DPP4 inhibitors should potentiate the impact of these strategies on GLP-1 levels. These strategies may have potential for optimising healthspan not just in diabetics and prediabetics, but in the general population.

Contributors MFM and JJDN are solely responsible for the conception and writing of this review.

Competing interests MFM is owner and science director of the small nutraceutical company NutriGuard Research, which sells glucomannan.
Provenance and peer review Not commissioned; externally peer reviewed.

Data sharing statement No additional data are available.

Open Access This is an Open Access article distributed in accordance with the Creative Commons Attribution Non Commercial (CC BY-NC 4.0) license, which permits others to distribute, remix, adapt, build upon this work noncommercially, and license their derivative works on different terms, provided the original work is properly cited and the use is non-commercial. See: http:// creativecommons.org/licenses/by-nc/4.0/

\section{REFERENCES}

1. Puls W, Keup U, Krause HP, et al. Glucosidase inhibition. A new approach to the treatment of diabetes, obesity, and hyperlipoproteinaemia. Naturwissenschaften 1977;64:536-7.

2. Hanefeld M, Schaper F, Koehler C. Effect of acarbose on vascular disease in patients with abnormal glucose tolerance. Cardiovasc Drugs Ther 2008;22:225-31.

3. Ferey-Roux G, Perrier J, Forest E, et al. The human pancreatic alpha-amylase isoforms: isolation, structural studies and kinetics of inhibition by acarbose. Biochim Biophys Acta 1998;1388:10-20.

4. Heine RJ, Balkau B, Ceriello A, et al. What does postprandial hyperglycaemia mean? Diabet Med 2004;21:208-13.

5. Standl E, Schnell O, Ceriello A. Postprandial hyperglycemia and glycemic variability: should we care? Diabetes Care 2011;34(Suppl 2):S120-7.

6. Van de Laar FA, Lucassen PL, Akkermans RP, et al. Alpha-glucosidase inhibitors for patients with type 2 diabetes: results from a Cochrane systematic review and meta-analysis. Diabetes Care 2005;28:154-63.

7. Zhu Q, Tong $\mathrm{Y}, \mathrm{Wu} \mathrm{T}$, et al. Comparison of the hypoglycemic effect of acarbose monotherapy in patients with type 2 diabetes mellitus consuming an Eastern or Western diet: a systematic meta-analysis. Clin Ther 2013;35:880-99.

8. Godbout A, Chiasson JL. Who should benefit from the use of alpha-glucosidase inhibitors? Curr Diab Rep 2007;7:333-9.

9. Pan CY, Gao Y, Chen JW, et al. Efficacy of acarbose in Chinese subjects with impaired glucose tolerance. Diabetes Res Clin Pract 2003;61:183-90.

10. Pan C, Yang W, Barona JP, et al. Comparison of vildagliptin and acarbose monotherapy in patients with type 2 diabetes: a 24-week, double-blind, randomized trial. Diabet Med 2008;25:435-41.

11. Nakhaee A, Sanjari M. Evaluation of effect of acarbose consumption on weight losing in non-diabetic overweight or obese patients in Kerman. J Res Med Sci 2013;18:391-4.

12. Standl E, Theodorakis MJ, Erbach M, et al. On the potential of acarbose to reduce cardiovascular disease. Cardiovasc Diabetol 2014;13:81.

13. Chiasson JL, Josse RG, Gomis R, et al. Acarbose for prevention of type 2 diabetes mellitus: the STOP-NIDDM randomised trial. Lancet 2002;359:2072-7.

14. Chiasson JL, Josse RG, Gomis R, et al. Acarbose treatment and the risk of cardiovascular disease and hypertension in patients with impaired glucose tolerance: the STOP-NIDDM trial. JAMA 2003;290:486-94.

15. Hanefeld M, Cagatay M, Petrowitsch T, et al. Acarbose reduces the risk for myocardial infarction in type 2 diabetic patients: metaanalysis of seven long-term studies. Eur Heart $J$ 2004;25:10-16.

16. Holman RR, Bethel MA, Chan JC, et al. Rationale for and design of the Acarbose Cardiovascular Evaluation (ACE) trial. Am Heart $J$ 2014;168:23-9.

17. Rosenbaum P, Peres RB, Zanella MT, et al. Improved glycemic control by acarbose therapy in hypertensive diabetic patients: effects on blood pressure and hormonal parameters. Braz J Med Biol Res 2002;35:877-84.

18. Jian ZJ, Zhou BY. Efficacy and safety of acarbose in the treatment of elderly patients with postprandial hypotension. Chin Med $J$ (Engl) 2008;121:2054-9.

19. Gentilcore D, Vanis L, Wishart JM, et al. The alpha (alpha)glucosidase inhibitor, acarbose, attenuates the blood pressure and splanchnic blood flow responses to intraduodenal sucrose in older adults. J Gerontol A Biol Sci Med Sci 2011;66:917-24.

20. Santilli F, Formoso G, Sbraccia P, et al. Postprandial hyperglycemia is a determinant of platelet activation in early type 2 diabetes mellitus. J Thromb Haemost 2010;8:828-37.

21. Hanefeld M, Chiasson JL, Koehler C, et al. Acarbose slows progression of intima-media thickness of the carotid arteries in subjects with impaired glucose tolerance. Stroke 2004;35:1073-8. 
22. Koyasu $\mathrm{M}$, Ishii $\mathrm{H}$, Watarai $\mathrm{M}$, et al. Impact of acarbose on carotid intima-media thickness in patients with newly diagnosed impaired glucose tolerance or mild type 2 diabetes mellitus: a one-year, prospective, randomized, open-label, parallel-group study in Japanese adults with established coronary artery disease. Clin Ther 2010;32:1610-17.

23. Patel YR, Kirkman MS, Considine RV, et al. Effect of acarbose to delay progression of carotid intima-media thickness in early diabetes. Diabetes Metab Res Rev 2013;29:582-91.

24. Wascher TC, Schmoelzer I, Wiegratz A, et al. Reduction of postchallenge hyperglycaemia prevents acute endothelial dysfunction in subjects with impaired glucose tolerance. Eur J Clin Invest 2005;35:551-7.

25. Minatoguchi S, Zhang Z, Bao N, et al. Acarbose reduces myocardial infarct size by preventing postprandial hyperglycemia and hydroxyl radical production and opening mitochondrial KATP channels in rabbits. J Cardiovasc Pharmacol 2009;54:25-30.

26. Harrison DE, Strong R, Allison DB, et al. Acarbose, 17-alpha-estradiol, and nordihydroguaiaretic acid extend mouse lifespan preferentially in males. Aging Cell 2014;13:273-82.

27. Bartke A. Minireview: role of the growth hormone/insulin-like growth factor system in mammalian aging. Endocrinology 2005;146:3718-23.

28. Inagaki T, Lin VY, Goetz R, et al. Inhibition of growth hormone signaling by the fasting-induced hormone FGF21. Cell Metab 2008;8:77-83.

29. Yu J, Zhao L, Wang A, et al. Growth hormone stimulates transcription of the fibroblast growth factor 21 gene in the live through the signal transducer and activator of transcription 5 . Endocrinology 2012;153:750-8.

30. Kralisch S, Tonjes A, Krause K, et al. Fibroblast growth factor-21 serum concentrations are associated with metabolic and hepatic markers in humans. J Endocrinol 2013;216:135-43.

31. Zhang Y, Xie Y, Berglund ED, et al. The starvation hormone, fibroblast growth factor-21, extends lifespan in mice. Elife 2012;1: e00065.

32. Mendelsohn AR, Larrick JW. Fibroblast growth factor-21 is a promising dietary restriction mimetic. Rejuvenation Res 2012;15:624-8.

33. Qualmann C, Nauck MA, Holst JJ, et al. Glucagon-like peptide 1 (7-36 amide) secretion in response to luminal sucrose from the upper and lower gut. A study using alpha-glucosidase inhibition (acarbose). Scand J Gastroenterol 1995;30:892-6.

34. Seifarth C, Bergmann J, Holst JJ, et al. Prolonged and enhanced secretion of glucagon-like peptide 1 (7-36 amide) after oral sucrose due to alpha-glucosidase inhibition (acarbose) in type 2 diabetic patients. Diabet Med 1998;15:485-91.

35. Enc FY, Imeryuz N, Akin L, et al. Inhibition of gastric emptying by acarbose is correlated with GLP-1 response and accompanied by CCK release. Am J Physiol Gastrointest Liver Physiol 2001;281: G752-63.

36. Lee A, Patrick P, Wishart J, et al. The effects of miglitol on glucagon-like peptide-1 secretion and appetite sensations in obese type 2 diabetics. Diabetes Obes Metab 2002;4:329-35.

37. Arakawa M, Ebato C, Mita T, et al. Miglitol suppresses the postprandial increase in interleukin 6 and enhances active glucagon-like peptide 1 secretion in viscerally obese subjects. Metabolism 2008;57:1299-306.

38. Zheng MY, Yang JH, Shan CY, et al. Effects of 24-week treatment with acarbose on glucagon-like peptide 1 in newly diagnosed type 2 diabetic patients: a preliminary report. Cardiovasc Diabetol 2013;12:73.

39. Yang M, Zhang L, Wang C, et al. Liraglutide increases FGF-21 activity and insulin sensitivity in high fat diet and adiponectin knockdown induced insulin resistance. PLOS ONE 2012;7:e48392.

40. Nonogaki K, Hazama M, Satoh N. Liraglutide suppresses obesity and hyperglycemia associated with increases in hepatic fibroblast growth factor 21 production in KKAy mice. Biomed Res Int 2014;2014:751930.

41. Lundasen T, Hunt MC, Nilsson LM, et al. PPARalpha is a key regulator of hepatic FGF21. Biochem Biophys Res Commun 2007;360:437-40.

42. Galman C, Lundasen T, Kharitonenkov A, et al. The circulating metabolic regulator FGF21 is induced by prolonged fasting and PPARalpha activation in man. Cell Metab 2008;8:169-74.

43. Ong KL, Rye KA, O'Connell R, et al. Long-term fenofibrate therapy increases fibroblast growth factor 21 and retinol-binding protein 4 in subjects with type 2 diabetes. J Clin Endocrinol Metab 2012;97:4701-8.

44. Purushotham A, Schug TT, Xu Q, et al. Hepatocyte-specific deletion of SIRT1 alters fatty acid metabolism and results in hepatic steatosis and inflammation. Cell Metab 2009;9:327-38.
45. Li Y, Wong K, Giles A, et al. Hepatic SIRT1 attenuates hepatic steatosis and controls energy balance in mice by inducing fibroblast growth factor 21. Gastroenterology 2014;146:539-49.

46. Ding X, Saxena NK, Lin S, et al. Exendin-4, a glucagon-like protein-1 (GLP-1) receptor agonist, reverses hepatic steatosis in ob/ ob mice. Hepatology 2006;43:173-81.

47. Svegliati-Baroni G, Saccomanno S, Rychlicki C, et al. Glucagonlike peptide-1 receptor activation stimulates hepatic lipid oxidation and restores hepatic signalling alteration induced by a high-fat diet in nonalcoholic steatohepatitis. Liver Int 2011;31:1285-97.

48. Pachikian BD, Essaghir A, Demoulin JB, et al. Prebiotic approach alleviates hepatic steatosis: implication of fatty acid oxidative and cholesterol synthesis pathways. Mol Nutr Food Res 2013;57:347-59.

49. Ceriello A, Esposito K, Piconi L, et al. Oscillating glucose is more deleterious to endothelial function and oxidative stress than mean glucose in normal and type 2 diabetic patients. Diabetes 2008;57:1349-54.

50. Quagliaro L, Piconi L, Assaloni R, et al. Intermittent high glucose enhances apoptosis related to oxidative stress in human umbilical vein endothelial cells: the role of protein kinase $C$ and $N A D(P)$ $\mathrm{H}$-oxidase activation. Diabetes 2003:52:2795-804

51. Quagliaro L, Piconi L, Assaloni R, et al. Intermittent high glucose enhances ICAM-1, VCAM-1 and E-selectin expression in human umbilical vein endothelial cells in culture: the distinct role of protein kinase $\mathrm{C}$ and mitochondrial superoxide production. Atherosclerosis 2005;183:259-67.

52. Quagliaro L, Piconi L, Assaloni R, et al. Primary role of superoxide anion generation in the cascade of events leading to endothelial dysfunction and damage in high glucose treated HUVEC. Nutr Metab Cardiovasc Dis 2007;17:257-67.

53. Monnier L, Mas E, Ginet C, et al. Activation of oxidative stress by acute glucose fluctuations compared with sustained chronic hyperglycemia in patients with type 2 diabetes. JAMA 2006;295:1681-7.

54. Schisano B, Tripathi G, McGee K, et al. Glucose oscillations, more than constant high glucose, induce p53 activation and a metabolic memory in human endothelial cells. Diabetologia 2011;54:1219-26.

55. Kim JW, Yoon KH. Glucolipotoxicity in Pancreatic beta-Cells. Diabetes Metab J 2011;35:444-50.

56. Hattori $Y$, Jojima T, Tomizawa A, et al. A glucagon-like peptide-1 (GLP-1) analogue, liraglutide, upregulates nitric oxide production and exerts anti-inflammatory action in endothelial cells. Diabetologia 2010;53:2256-63.

57. Gaspari T, Liu H, Welungoda I, et al. A GLP-1 receptor agonist liraglutide inhibits endothelial cell dysfunction and vascular adhesion molecule expression in an ApoE-/- mouse model. Diab Vasc Dis Res 2011;8:117-24.

58. Ding L, Zhang J. Glucagon-like peptide-1 activates endothelial nitric oxide synthase in human umbilical vein endothelial cells. Acta Pharmacol Sin 2012;33:75-81.

59. Krasner NM, Ido Y, Ruderman NB, et al. Glucagon-like peptide-1 (GLP-1) analog liraglutide inhibits endothelial cell inflammation through a calcium and AMPK dependent mechanism. PLOS ONE 2014;9:e97554.

60. Ben-Shlomo S, Zvibel I, Shnell M, et al. Glucagon-like peptide-1 reduces hepatic lipogenesis via activation of AMP-activated protein kinase. J Hepatol 2011;54:1214-23.

61. Trevaskis JL, Griffin PS, Wittmer C, et al. Glucagon-like peptide-1 receptor agonism improves metabolic, biochemical, and histopathological indices of nonalcoholic steatohepatitis in mice. Am J Physiol Gastrointest Liver Physiol 2012;302:G762-72.

62. Lee J, Hong SW, Rhee EJ, et al. GLP-1 receptor agonist and non-alcoholic fatty liver disease. Diabetes Metab J 2012;36:262-7.

63. Cuthbertson DJ, Irwin A, Gardner CJ, et al. Improved glycaemia correlates with liver fat reduction in obese, type 2 diabetes, patients given glucagon-like peptide-1 (GLP-1) receptor agonists. PLoS ONE 2012;7:e50117.

64. Eguchi $\mathrm{Y}$, Kitajima $\mathrm{Y}, \mathrm{Hyogo} \mathrm{H}$, et al. Pilot study of liraglutide effects in non-alcoholic steatohepatitis and non-alcoholic fatty liver disease with glucose intolerance in Japanese patients (LEAN-J). Hepatol Res. Published Online First: 4 May 2014. doi:10.1111/ hepr.12351.

65. Yamagishi S, Nakamura K, Inoue $\mathrm{H}$. Acarbose is a promising therapeutic strategy for the treatment of patients with nonalcoholic steatohepatitis (NASH). Med Hypotheses 2005;65:377-9.

66. Moreno JL, Willett KC, Desilets AR. Exenatide as a novel weight loss modality in patients without diabetes. Ann Pharmacother 2012;46:1700-6

67. Ottney A. Glucagon-like peptide-1 receptor agonists for weight loss in adult patients without diabetes. Am J Health Syst Pharm 2013;70:2097-103. 
68. Bose AK, Mocanu MM, Carr RD, et al. Glucagon like peptide- 1 is protective against myocardial ischemia/reperfusion injury when given either as a preconditioning mimetic or at reperfusion in an isolated rat heart model. Cardiovasc Drugs Ther 2005;19:9-11.

69. Fields AV, Patterson B, Karnik AA, et al. Glucagon-like peptide-1 and myocardial protection: more than glycemic control. Clin Cardiol 2009;32:236-43.

70. Read PA, Hoole SP, White PA, et al. A pilot study to assess whether glucagon-like peptide-1 protects the heart from ischemic dysfunction and attenuates stunning after coronary balloon occlusion in humans. Circ Cardiovasc Interv 2011;4:266-72.

71. Birnbaum $\mathrm{Y}, \mathrm{Ye} \mathrm{Y}$, Bajaj M. Myocardial protection against ischemia-reperfusion injury by GLP-1: molecular mechanisms. Metab Syndr Relat Disord 2012;10:387-90.

72. Kai Z, Yongbo W, Lin Z, et al. Exendin-4 attenuates ischemia-induced ventricular arrhythmias in rats. Cardiol $J$ 2013;20:29-33.

73. Testai L, Rapposelli S, Calderone V. Cardiac ATP-sensitive potassium channels: a potential target for an anti-ischaemic pharmacological strategy. Cardiovasc Hematol Agents Med Chem 2007:5:79-90.

74. Buteau J, El-Assaad W, Rhodes CJ, et al. Glucagon-like peptide-1 prevents beta cell glucolipotoxicity. Diabetologia 2004;47:806-15.

75. Wang HW, Mizuta M, Saitoh Y, et al. Glucagon-like peptide-1 and candesartan additively improve glucolipotoxicity in pancreatic beta-cells. Metabolism 2011;60:1081-9.

76. Shimoda M, Kanda Y, Hamamoto S, et al. The human glucagon-like peptide-1 analogue liraglutide preserves pancreatic beta cells via regulation of cell kinetics and suppression of oxidative and endoplasmic reticulum stress in a mouse model of diabetes. Diabetologia 2011:54:1098-108.

77. Xiong $X$, Shao $W$, Jin T. New insight into the mechanisms underlying the function of the incretin hormone glucagon-like peptide-1 in pancreatic beta-cells: the involvement of the Wnt signaling pathway effector beta-catenin. Islets 2012;4:359-65.

78. Miao XY, Gu ZY, Liu P, et al. The human glucagon-like peptide-1 analogue liraglutide regulates pancreatic beta-cell proliferation and apoptosis via an AMPK/mTOR/P70S6K signaling pathway. Peptides 2013;39:71-9.

79. During MJ, Cao L, Zuzga DS, et al. Glucagon-like peptide-1 receptor is involved in learning and neuroprotection. Nat Med 2003;9:1173-9.

80. Harkavyi A, Whitton PS. Glucagon-like peptide 1 receptor stimulation as a means of neuroprotection. Br J Pharmacol 2010;159:495-501.

81. Teramoto S, Miyamoto N, Yatomi K, et al. Exendin-4, a glucagon-like peptide-1 receptor agonist, provides neuroprotection in mice transient focal cerebral ischemia. $J$ Cereb Blood Flow Metab 2011;31:1696-705.

82. Holscher C. Potential role of glucagon-like peptide-1 (GLP-1) in neuroprotection. CNS Drugs 2012;26:871-82.

83. McClean PL, Holscher C. Liraglutide can reverse memory impairment, synaptic loss and reduce plaque load in aged APP/ PS1 mice, a model of Alzheimer's disease. Neuropharmacology 2014;76(Pt A):57-67.

84. Xiong $\mathrm{H}$, Zheng $\mathrm{C}$, Wang $\mathrm{J}$, et al. The neuroprotection of liraglutide on Alzheimer-like learning and memory impairment by modulating the hyperphosphorylation of tau and neurofilament proteins and insulin signaling pathways in mice. J Alzheimers Dis 2013;37:623-35.

85. Darsalia V, Nathanson D, Nystrom T, et al. GLP-1R activation for the treatment of stroke: updating and future perspectives. Rev Endocr Metab Disord 2014;15:233-42.

86. McClean PL, Holscher C. Lixisenatide, a drug developed to treat type 2 diabetes, shows neuroprotective effects in a mouse model of Alzheimer's disease. Neuropharmacology 2014;86C:241-58.

87. Jenkins DJ. Lente carbohydrate: a newer approach to the dietary management of diabetes. Diabetes Care 1982;5:634-41.

88. Jenkins DJ, Kendall CW, Augustin LS, et al. High-complex carbohydrate or lente carbohydrate foods?. Am J Med 2002; 113(Suppl 9B):30S-7S.
89. Jenkins DJ, Wolever TM, Jenkins AL. Starchy foods and glycemic index. Diabetes Care 1988;11:149-59.

90. Doi K. Effect of konjac fibre (glucomannan) on glucose and lipids. Eur J Clin Nutr 1995:49(Suppl 3):S190-7.

91. Doi K, Matsuura M, Kawara A, et al. Treatment of diabetes with glucomannan (konjac mannan). Lancet 1979;1:987-8.

92. Vuksan V, Jenkins DJ, Spadafora $P$, et al. Konjac-mannan (glucomannan) improves glycemia and other associated risk factors for coronary heart disease in type 2 diabetes. A randomized controlled metabolic trial. Diabetes Care 1999;22:913-19.

93. Chen HL, Sheu WH, Tai TS, et al. Konjac supplement alleviated hypercholesterolemia and hyperglycemia in type 2 diabetic subjects -a randomized double-blind trial. J Am Coll Nutr 2003;22:36-42.

94. Chearskul S, Sangurai S, Nitiyanant W, et al. Glycemic and lipid responses to glucomannan in Thais with type 2 diabetes mellitus. $J$ Med Assoc Thai 2007;90:2150-7.

95. Celleno L, Tolaini MV, D'Amore A, et al. A Dietary supplement containing standardized Phaseolus vulgaris extract influences body composition of overweight men and women. Int J Med Sci 2007;4:45-52.

96. Udani JK, Singh BB, Barrett ML, et al. Lowering the glycemic index of white bread using a white bean extract. Nutr J 2009;8:52.

97. Preuss HG. Bean amylase inhibitor and other carbohydrate absorption blockers: effects on diabesity and general health. J Am Coll Nutr 2009;28:266-76.

98. Barrett ML, Udani JK. A proprietary alpha-amylase inhibitor from white bean (Phaseolus vulgaris): a review of clinical studies on weight loss and glycemic control. Nutr J 2011;10:24.

99. Shima K, Tanaka A, Ikegami H, et al. Effect of dietary fiber, glucomannan, on absorption of sulfonylurea in man. Horm Metab Res 1983;15:1-3.

100. Doi K, Matsuura M, Kawara A, et al. Influence of dietary fiber (konjac mannan) on absorption of vitamin B12 and vitamin E. Tohoku J Exp Med 1983:141(Suppl):677-81.

101. Cani PD, Lecourt E, Dewulf EM, et al. Gut microbiota fermentation of prebiotics increases satietogenic and incretin gut peptide production with consequences for appetite sensation and glucose response after a meal. Am J Clin Nutr 2009;90:1236-43.

102. Shen L, Keenan MJ, Raggio A, et al. Dietary-resistant starch improves maternal glycemic control in Goto-Kakizaki rat. Mol Nutr Food Res 2011;55:1499-508.

103. Everard A, Lazarevic V, Derrien M, et al. Responses of gut microbiota and glucose and lipid metabolism to prebiotics in genetic obese and diet-induced leptin-resistant mice. Diabetes 2011;60:2775-86.

104. Everard A, Cani PD. Gut microbiota and GLP-1. Rev Endocr Metab Disord 2014:15:189-96.

105. Tolhurst G, Heffron H, Lam YS, et al. Short-chain fatty acids stimulate glucagon-like peptide-1 secretion via the G-protein-coupled receptor FFAR2. Diabetes 2012;61:364-71.

106. Yadav $\mathrm{H}$, Lee $\mathrm{JH}$, Lloyd $\mathrm{J}$, et al. Beneficial metabolic effects of a probiotic via butyrate-induced GLP-1 hormone secretion. J Biol Chem 2013:288:25088-97.

107. Gameiro A, Reimann F, Habib AM, et al. The neurotransmitters glycine and GABA stimulate glucagon-like peptide-1 release from the GLUTag cell line. J Physiol 2005;569(Pt 3):761-72.

108. El HM, Perez I, Zamora J, et al. Glycine intake decreases plasma free fatty acids, adipose cell size, and blood pressure in sucrose-fed rats. Am J Physiol Regul Integr Comp Physiol 2004;287:R1387-93.

109. Ruiz-Ramirez A, Ortiz-Balderas E, Cardozo-Saldana G, et al. Glycine restores glutathione and protects against oxidative stress in vascular tissue from sucrose-fed rats. Clin Sci (Lond) 2014;126:19-29.

110. Mells JE, Fu PP, Sharma S, et al. Glp-1 analog, liraglutide, ameliorates hepatic steatosis and cardiac hypertrophy in C57BL/6J mice fed a Western diet. Am J Physiol Gastrointest Liver Physiol 2012;302:G225-35.

111. Horikawa $\mathrm{Y}$, Enya $\mathrm{M}$, lizuka $\mathrm{K}$, et al. Synergistic effect of alpha-glucosidase inhibitors and dipeptidyl peptidase 4 inhibitor treatment. J Diabetes Investig 2011;2:200-3. 